\title{
Real-time Optimization and Increasing Efficiency of the Processes in the Petrochemical Industry
}

\author{
Kireeva E. ${ }^{1}$, Kireev M. ${ }^{2}$ \\ ${ }^{1}$ Plekhanov Russian University of Economics, Moscow, Russian Federation, Scopus id: 57196477300, \\ kevmosc@mail.ru \\ ${ }^{2}$ Business Development Manager, Turbomachinery Controls (TMC), Functional Safety Engineer (TUV \\ Rheinland ASI, \#10345/15, SIS), «Schneider Electric», 115504 Moscow, Russian Federation, \\ kireev.max@mail.ru
}

\begin{abstract}
APC solution is designed to coexist in parallel with existing systems, such as MES, ERP as well as DCS, complementing them. Moreover, without the presence of a properly functioning of DCS, it is premature to talk about the transition to APC.

APC solutions integrate with existing distributed control systems (DCS) for optimal plant control. The idea of the model is to build a mathematical representation of the controlled process and integrate this model in the control loop in real time mode. It is worth saying that in addition to mathematical models, which are the "calling card" of the solutions offered on the APC market, APC also uses other methods of modern automation. One example of the effective using of APC in process is stabilization problems, which can be solved using the classic PID control, but by using a modern APC solution, the problem can be solved more efficiently, for example, by not just stabilizing the process, but stabilizing it in a technologically feasible and at the same time the most cost-effective state of equilibrium. This process is called "stock removal by quality".
\end{abstract}

Key words: APC, control system, DCS, efficiency.

\section{INTRODUCTION}

Improving the efficiency of processes at existing refineries is one of the priorities and challenging tasks of the oil and gas, petrochemical and chemical industries. This task becomes especially urgent during periods of crisis in the economy, when capital-intensive ways to increase production capacity are very limited. One of the most successful and cost-effective methods of increasing the efficiency of continuous technological processes has been the implementation of advanced process control (APC) systems [1]. The role of information technology in the automation of processes is difficult to overestimate - it is almost impossible to imagine up-to-date plant without integrated IT systems, such as ERP, MES and Distributed control systems (DCS).

\subsection{APC}

Advanced process control system (APC) is a hardware and software complex that is an add-on to the basic process control system (BPCS) and is designed to increase the efficiency of technological processes by improving the quality of management and continuous optimization of technical processes according to specified economic criteria [2]. Figure 1 shows comparison between systems.

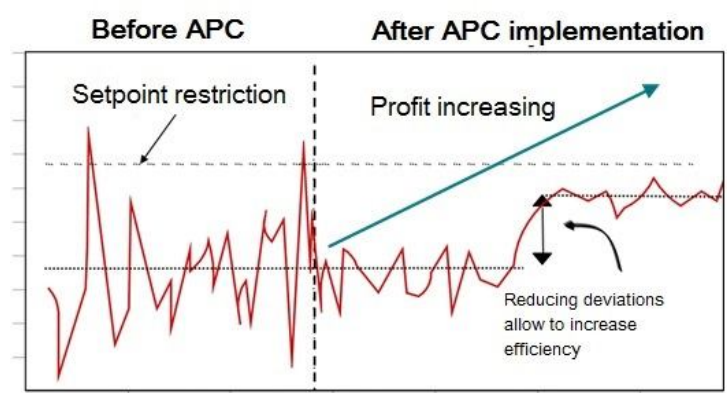

Figure 1: Comparison of classic distributed control system (DCS) and advanced process control (APC) system

\subsection{Up-to-date plant}

Changes in the market situation in many sectors - general saturation of the market and increased competition, the introduction of new environmental norms and standards, a general increase in the cost of production, high energy prices - all these and other reasons dictate the need for further development of automation in production, in particular, the transition to optimal management, first of all, on technical and economic indicators of production [3]. The class of systems that implement this in practice is called APC (Advanced Process Control).

The key goals of APC implementation are reducing losses and increasing production profit by bringing the entire chain of processes to the optimal operating mode. APC is an approach centered on an IT system that displays and maintains a plant operating mode that is optimal from a technical and economic point of view [4].

There are many examples of successful APC implementations in Western countries - for oil refineries, chemical, pulp and paper, metallurgical and energy fossil power plants, thus APC 
applications are expanding continuously, as the demand for technology in modern production is growing [5]. For the Russian market, APC is still a relatively new technology, and Schneider Electric offers an extensive experience and developments in this area.

\section{APC CONCEPT}

First of all, APC is an approach, it is a set of economic, technical and organizational measures, the ultimate goal of which is to increase the efficiency of a single installation or several related installations using non-technological methods (i.e. not by purchasing new equipment or updating existing), but by optimizing process control. APC is not just an IT solution, it is, first, a consulting project to identify new opportunities for optimal management of an existing technological process. Schneider Electric has adapted the western APC project management methodology to ensure successful implementation [6].

As mentioned above, the main issue solved by APC is increasing profits (per unit of processed raw materials or in annual terms) due to the optimization of processes. At the same time, the implementation of APC also addresses the task of reducing the expenditure component (for example, reducing energy consumption, optimizing the use of raw materials), and, if applicable, reducing equipment maintenance costs - for example, reducing catalyst wear [7]. There is a third component of each APC implementation, the so-called "uncountable profits", which can be briefly described as "intangible benefits from the project" - such as reducing accident rate, harmful emissions, equipment depreciation, the emergence of a "reserve of time" among operators, changing culture in the team towards production optimization and an overall increase in employee awareness of the process [8].

Often the third component is left overboard, which, in our opinion, is not entirely correct.

\section{COST-EFFECTIVE IMPLEMENTATION of APC SYSTEMS}

\subsection{The main target of APC}

The main target of APC is to bring the process plant to the maximum economy mode (maximum yield of the most valuable products, power consumption minimization, etc.) and maintaining this mode [9]. Therefore, the APC project should begin with a feasibility study, which includes an assessment of potential profits based on a rigorous analysis of plant operation data and an estimate of project costs. In this case, the operation of the installation should be analyzed considering the entire technological chain in which this installation is involved, since the "local" optimization of a separate technological conversion can give a negative result for the installation.

As a rule, when assessing potential benefits with APC, two main measures are cash profit per unit of processed raw materials or annual profit (usually in cash).

There are two main sources of profit. To the first (so-called countable profit) include an increase in the volume of processing, optimization of the yield of products, saving of resources (mainly energy) [10]. The second source (the so-called "uncountable" profit) involves the reduction of repair costs, emissions, accident rate (including through the fault of personnel); the emergence of a reserve of time for operators to perform other work efficiently; better staff awareness of the work of process, etc [11], [12].

According to the practical experience of Schneider Electric implementation, the profit from APC in percentage terms is estimated as follows: increase in production - by 1 ... 10\%; increase in the output of more valuable products - by $5 \ldots$ $15 \%$; reduction in production costs - by $1 \ldots 5 \%$; increased stability of the regime - by $50 \%$; reduction of the time of transition to a new technological mode - by $20 \ldots 60 \%$. The typical payback period for APC projects is 3 ... 6 months. In monetary terms, using the example of various technological units, the effect of the use of APC in millions of dollars per year per unit can be estimated as follows: atmospheric separation of oil - 4.0 ... 5.0, vacuum distillation - 1.0 ... 1.2, slow coking - $0.8 \ldots 1.0$, catalytic cracking - $3.5 \ldots$ 4.0 , catalytic reforming $-0.9 \ldots 1.1$, alkylation $-1.0 \ldots 1.2$, gasoline mixing - $2.5 \ldots 3.0$, steam production $-1.0 \ldots 1.5$, dewaxing oils - $0.8 \ldots 1.0$, ammonia production - more than 0.5 . Figure 2 shows the comparative economic effect that can be obtained using various sources of industrial automation. As you can see, the lion's share of the effect (up to 65\% of all that is possible) can be obtained through APC. In this case, the necessary investments in the amount of only $20 \%$ of the total [13]. In other words, APC projects are the most effective. At the same time, unfortunately, it is impossible to start them without the corresponding (and very significant) costs of basic and advanced regulation, as evidenced by the lower part of the schedule [14].

Leading vendors of APC systems have at their disposal the tools to evaluate this effect at the stage of a preliminary production survey. The assessments obtained at the stage of the preliminary analysis of the object serve as the basis for the post-project audit, i.e. confirmation of the actual effect obtained from the implementation of advanced management.

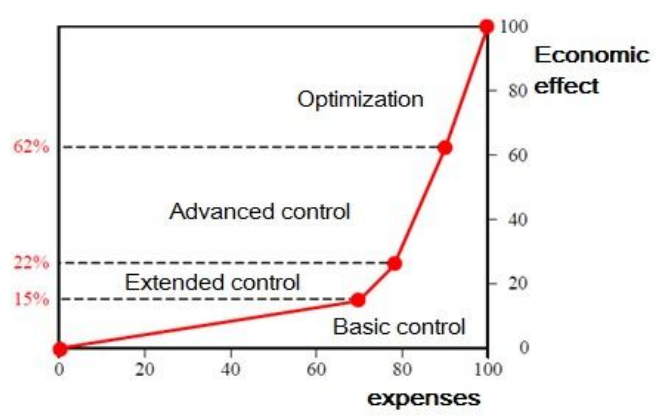

Figure 2: The economic effect given with APC implementation 
Kireeva E et al., International Journal of Emerging Trends in Engineering Research, 8(6), June 2020, 2878 - 2884

\subsection{APC's IT landscape}

What is unique in the APC solutions on the market? First, management based on predictive models of a control unit (or MPC: Model Predictive Control). The basic principles of operation of the multi-parameter controller MPC model in AVEVA APC [15]. Figure 3 shows presentation of the actual responses of the process in the form of a multi-parameter dynamic model. Each model predicts the direction, "shape" and size of the response. A model is developed by collecting information from process response tests.

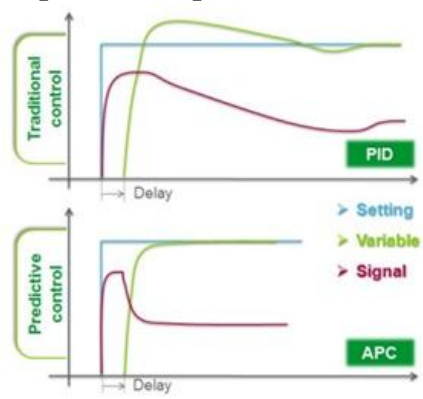

Figure 3: Representation of the actual responses of the process in the form of a multi-parameter dynamic model

The AVEVA APC math apparatus consists of five main steps. Initial data collection

At the first stage, data on the operation of the system is collected and a matrix of system responses is generated [16]. Figure show the matrix of changes in controlled variables (CV) when exposed to a manipulated variables (MV).

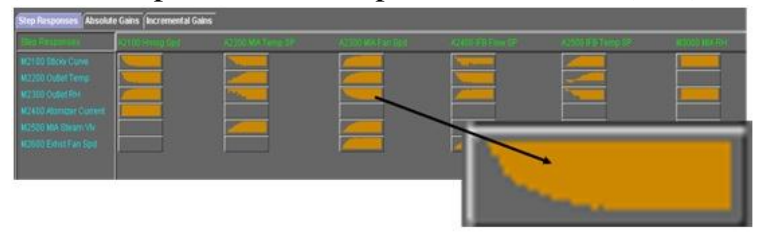

Figure 4: System response matrix

\subsection{Model definition}

Autoregressive component - the state of the system is determined based on previous states of the system with regressing coefficients.

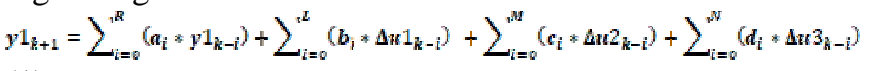

Component of the final impulse characteristics (FIC) - the state of the system is determined by the response to the instantaneous value of the input and the sum of all gradually decaying responses of previous signals that still affect the output [17]. Figure 5 shows the interaction of the components.

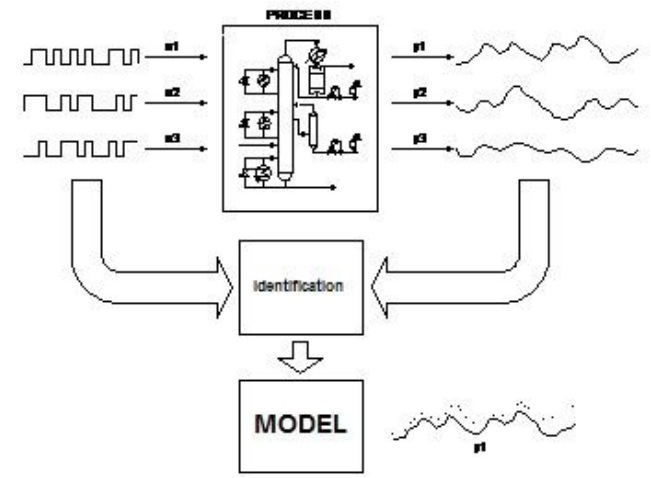

Figure 5: The interaction of the components of the APC system

\section{LEAST SQUARE METHOD}

The task is to find the best values of the parameters $b$ that bring the values of $f(x, b)$ as close as possible to the actual values of $\mathrm{y}$. It all comes down to solving an overdetermined system of equations for $b$ :

The essence of LSM is to find such parameters $b$ for which the sum of the squared deviations will be minimal: Figure 6 shows the result of the least squares method. Thus, we find all unknown parameters from the equations of the model and can predict the behavior of the system in the future:

$$
\begin{aligned}
& f\left(x_{t}, b\right)=y_{t}, \text { rде } t=1, \ldots, n \\
& \sum_{t=1}^{n}\left(y_{t}-f\left(x_{t}, b\right)\right)^{2} \rightarrow \min
\end{aligned}
$$

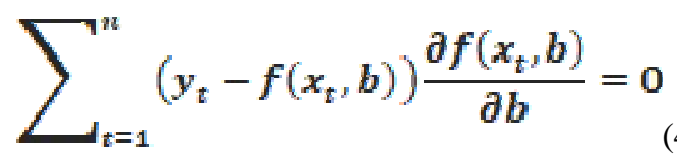

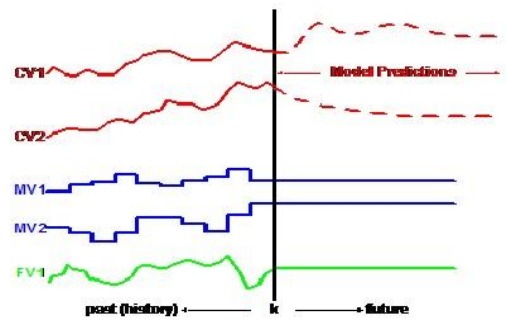

Figure 6: The result of LSM

The solution to the control problem. Quadratic programming Now we can predict the values of the controlled variables CV by defining certain manipulated variables MV.

The inverse problem is to determine the values of the manipulated variables MV to keep the controlled variables $\mathrm{CV}$ within the given boundaries. Figure 7 shows defining of MV. 


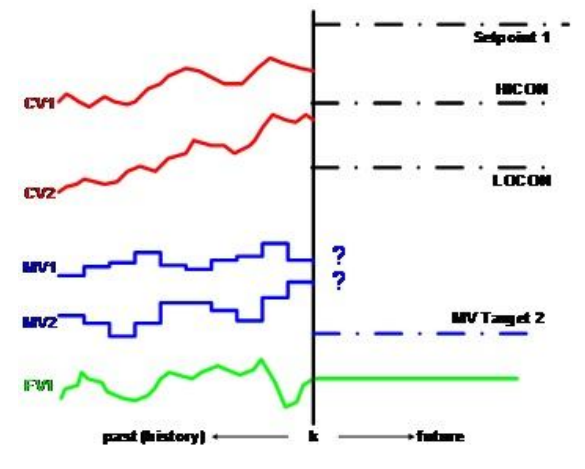

Figure 7: Defining of manipulated variables (MV)

$I=\sum_{i=0}^{N} \llbracket \vec{e}_{i+1}^{T} P \vec{e}_{i+1}+\overrightarrow{\Delta u}_{i+1}^{T} Q \overrightarrow{\Delta u}_{i+1}+\vec{f}_{i+1}^{T} R \vec{f}_{i+1} \rrbracket$

The process of solving the optimization problem (minimization or maximization) of a quadratic function of several variables with linear restrictions on these variables.

In short form, the solution has the form:

- MV limit such as: minimum value, maximum value, increment.

- Soft restrictions on CV. Soft restrictions may be violated so that a mathematical solution exists.

Figure 8 shows the result is a sequential set of steps for all MVs to achieve the required level of controlled $\mathrm{CV}$ variables.

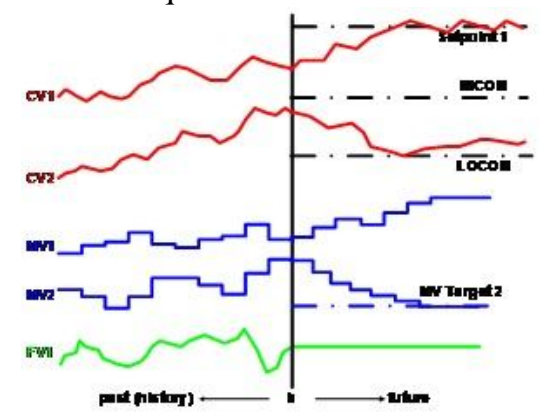

Figure 8: A sequential set of steps for all MVs

\section{THE OPTIMIZATION PROBLEM}

Figure 1 shows the optimization task is the calculation of cost-effective working conditions for the process, based on the determination of the economic value of each variable.

The solution is through linear programming in real time (Linear Programming, LP). LP implements limited optimization and maximizes the value of the "profit function", which expresses the overall economic effect of the process.

The LP solution is the established conditions for the process, namely a set of values for each of the variables under consideration, which (if applied) will lead to maximum economic benefit.

Virtual APC System Analyzers

Separately, it is worth noting that all modern APC solutions support working with virtual analyzers - mathematical models that allow, for example, to calculate the qualitative characteristics of a manufactured product based on directly measured data. This is especially true if there are no in-line analyzers or their readings are not reliable for real-time regulation. Virtual analyzers become sensors of APC solutions, based on deviations of their indicators, a real-time control action is carried out. It is important to understand that virtual analyzers, being models in their essence, can quantitatively reflect almost any production indicator that is not measured directly. To the question of the controlling effects of APC systems - if the deviation of the sensor readings exceeds a certain threshold, the mathematical model will calculate the corrective action and, through the software interface, will report the new target value to the PID controllers and bring the system to the optimal operating mode in the new conditions. Thus, the APC-system acts as a master controller, automatically calculating the control actions for optimal operation, and PID-controllers as slaves. Thus, by fine-tuning the system, the effects of external disturbances will be suppressed, and the process will work in close to optimal mode.

Figure 9 shows AVEVA APC solution used:

- Nonlinear models of the neural network.

- Linear models using partially the least squares method / principle of component analysis.

- The use of laboratory data to adjust the effect of disturbances.

- Values obtained from virtual analyzers can be used as controlled variables (CVs) in APC.

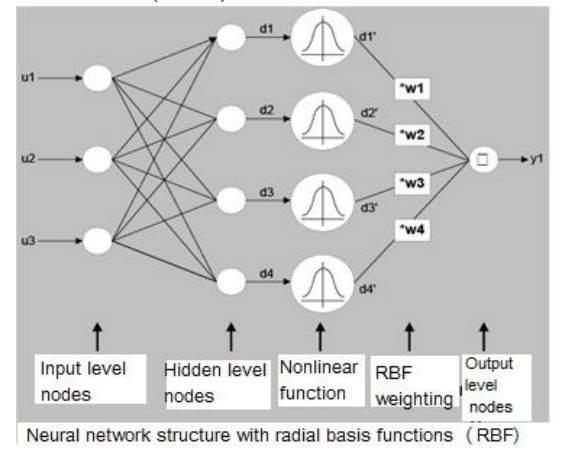

Figure 9: AVEVA APC virtual analyzers

An example of the implementation of AVEVA APC in the Russian Federation

The positive experience in implementation and operating the control system both worldwide and in Russia has led to a significant increase in interest in them from enterprises seeking to improve production efficiency. Such advanced enterprises include SIBUR. SIBUR is one of the largest integrated gas processing and petrochemical companies in Russia engaged in the processing of oil and gas production products into fuel and raw materials and synthetic materials. SIBUR owns and operates Russia's largest integrated infrastructure for the processing and transportation of associated gas and natural gas liquids, located mainly in 
Western Siberia, the largest Russian oil and gas producing region.

Hanging production efficiency is one of the main goals set by SIBUR. The company implements a range of various measures to achieve it. Events are of a different nature and are aimed, inter alia, at the introduction of new technologies, site separation ethane-propane fraction.

For each technological unit, the project provides a list of controlled parameters (CV) and constraints (LV), manipulated variables (MV) and optimization goals. Virtual analyzers of quality indicators of product fractions, which are part of the control system of the GFU unit, provide their calculation (assessment) in real time with a frequency of $10 \mathrm{~s}$, which is more than enough to control the inertial rectification process. Figure 9 shows that virtual analyzers are dependencies (mathematical models) between key indicators of product quality and process parameters. Figure 10 shows on the process flow chart which virtual analyzers were implemented were used during the design of the control system:

- propane content in dry gas.

- content of isobutane in the propane fraction.

- ethane content in the propane fraction.

- propane content in the isobutane fraction.

- butane content in the isobutane fraction.

- isobutane content in the butane fraction.

- pentane content in the isopentane fraction.

- isopentane content in the stable natural gasoline.

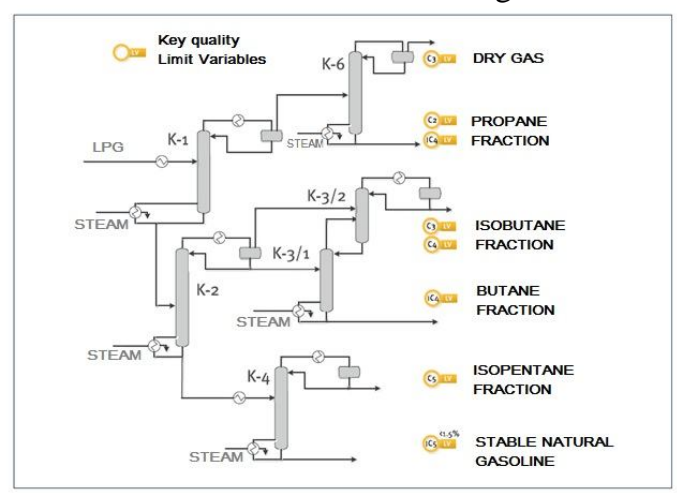

Figure 10: GFU unit flow chart with virtual analyzers

The quality of the implemented virtual analyzers is at a high level, which is confirmed during operation by a minimum deviation and a high degree of correlation with laboratory analysis data. The process control system receives all the necessary data from the process control system and transmits control actions and calculated information in the opposite direction with a frequency of $10 \mathrm{~s}$. From the Yokogawa Centum CS3000 DCS to the AVEVA APC control system, the following are transferred: setpoints from operator (SP), current values of the process parameters (PV), restrictions for the control system parameters, diagnostic parameters of the status of control loops, PID controller operating modes
(MODE), enable / disable signals multi-parameter controllers, watchdogs, laboratory test values. In the opposite direction are transmitted: the values of the settings for the slave PID controllers (SP_OUT), the state of the multi-parameter controllers, watchdogs, readings of virtual analyzers. Special algorithms for diagnosing data transmission, implemented both on the control system side and on the control system side, are used to assess the status of control loops and the reliability of transmitted input / output information, ensuring the reliability of the system. In the event of an emergency in which the operation of the control system is not possible, the diagnostic algorithms will automatically turn off the multi-parameter controllers, informing the operator about this and transfer the control system PID controllers to predefined operating modes and transferring control to the operator. Monitoring and determining the quality of work of the control system are based on the analysis of key performance indicators (KPI) of the functioning of both the system itself and the technological installation. Information on the effectiveness of the APC is presented in the form of reports in MS Excel format. To build reports, AVEVA APC Reporter software is used. These reports are used in the maintenance and continuous improvement of the quality of the control system and the technological installation. Reports can be generated both "on demand" for a specified period, and automatically for a certain period (shift, day, month, etc.). The information contained in the reports is provided in a convenient tabular and graphical form and can be modified in accordance with the wishes of the customer. The standard report includes data on the operation of virtual analyzers, data on the operation of each multi-parameter controller, summary reports on key indicators of the quality and overall performance of the installation. Analysis of the effectiveness of the control system is carried out by comparing the current values of KPI indicators with predetermined restrictions. There is a standard set of key parameters for the effectiveness of the control system. During the implementation of the project, the specified set is supplemented with key parameters of the efficiency of the technological installation.

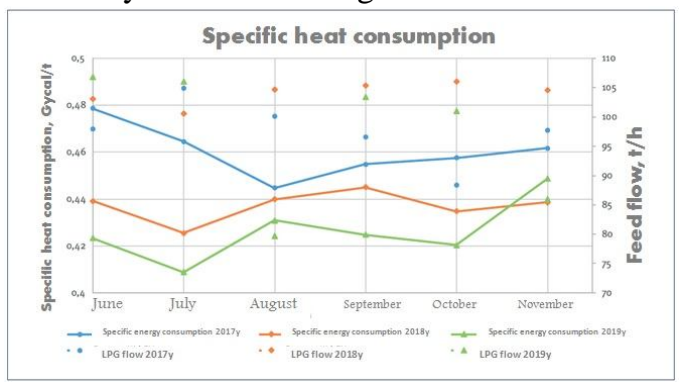

Figure 11: Comparison of the specific heat consumption of the installation before and after the introduction of the advanced process control (APC)

\section{Dynamic simulation}

Advanced Process Control (APC) provides strict control of key process variables based on a dynamic model. This 
Kireeva E et al., International Journal of Emerging Trends in Engineering Research, 8(6), June 2020, 2878 - 2884

eliminates the mutual influence and mismatch of the operation of individual control loops. As a result, production processes become more efficient - and economic benefits increase. As part of the project, a high-fidelity dynamic model of the process was developed in the DYNSIM Sim Sci software. Figure 12 shows the dynamic model in the software environment.

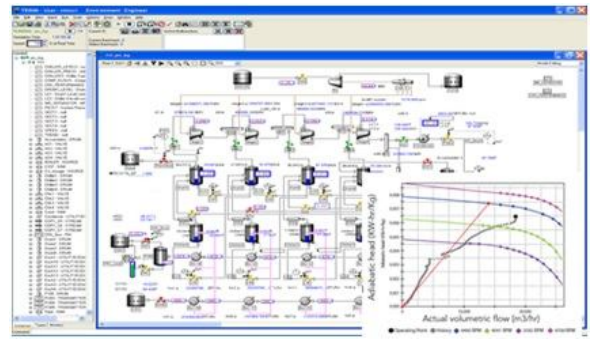

Figure 12: Dynamic model of gas fractionation unit

\section{THE ECONOMIC EFFECT OF IMPLEMENTING AVEVA APC}

The introduction of the process control system at the installation of the Central Federal State Institution Uralorgsintez showed the high efficiency of this solution. The declared economic effect was fully confirmed after the implementation of the AVEVA APC. The overall economic effect of the introduction of the process control system at the GFU unit amounted to $\$ 948,036,112$ / year. Figure 11 shows the effect which was obtained by reducing the consumption of thermal energy used for heating the columns, while maintaining the basic technological limitations and specifications for the quality of the products obtained. The estimated payback period was five months. The successful implementation of the control system was facilitated by the professionalism and support of the staff of plant, the laboratory of the plant, and the specialists of SIBUR. The SIBUR company is carrying out systematic work to develop this area at its facilities: new projects are underway to create a process control system, work is underway to examine technological facilities for the feasibility of implementing such systems. These events make a significant contribution to the development of the enterprise and significantly increase production efficiency.

\section{CONCLUSION}

To summarize all the above, APC is more a set of methods than just software, which includes reorienting the culture of the entire enterprise to optimize existing processes. At the core of the APC solution is a software package that is tightly integrated with existing DCS and works on complex mathematical models.

\section{REFERENCES}

1. Z. Gao, "On the centrality of disturbance rejection in automatic control," ISA Trans., vol. 4, no. 53, pp. 850-857, Jul. 2014. https://doi.org/10.1016/j.isatra.2013.09.012

2. Ara, A.L., Tolabi, H.B. and Hosseini, R., "Dynamic modeling and controller design of distribution static compensator in a microgrid based on combination of fuzzy set and galaxy-based search algorithm", International Journal of Engineering-Transactions A: Basics, Vol. 29, No. 10, (2016), 1392-1400. https://doi.org/10.5829/idosi.ije.2016.29.10a.10

3. G. Amendola, I. Dimino, A. Concilio, G. Andreutti, R. Pecora, and M. L. Cascio, «Preliminary Design Process for an Adaptive Winglet», International Journal of Mechanical Engineering and Robotics Research, vol. 7.1, pp. 83-93, Jan. 2018.

4. S. H. Li, J. Yang, W.-H. Chen, and X. S. Chen, Disturbance Observer, Based Control: Methods and Applications. Boca Raton, FL, USA: CRC Press, 2014.

5. Nojoumi A, Givehchi S. Identifying and Prioritizing Factors that Affect Technological Hazards in the Iranian Gas Refining Industry using Multi-criteria Decisionmaking Techniques (Case Study: South Pars Gas Complex). Indian Journal of Science and Technology. 2015. Vol. 8, 20: 34-35.

6. W. E. Wong, R. Gao, Y. Li, R. Abreu, and F. Wotawa, "A Survey on Software Fault Localization," IEEE Transactions on Software Engineering, vol. 42, no. 8, pp. 707-740, August 2016.

https://doi.org/10.1109/TSE.2016.2521368

7. O. Rivera, M. Mauledoux, A. Valencia, R. Jimenez, O. Avilé Hardware in Loop of a Generalized Predictive Controller for a Micro Grid DC System of Renewable Energy Sources / IJE TRANSACTIONS B: Applications Vol. 31, No. 8, (August 2018) 1215-1221.

8. Grèze L, Pellerin R, Leclaire P, N. Perrier N. Evaluating the effectiveness of task P. Clements and L. Northrop, "Software Product Lines: Practices and Patterns," Addison-Wesley Longman Publishing Co., Inc., Boston, 2001

9. D.L. Quang, H.J. Kang, and T.D. Le, «An Adaptive Controller with An Orthogonal Neural Network and A Third Order Sliding Mode Observer for Robot Manipulators», International Journal of Mechanical Engineering and Robotics Research, vol. 7.2, pp.169-174, Jan. 2018. https://doi.org/10.18178/ijmerr.7.2.169-173

10. H. Poor, An Introduction to Signal Detection and Estimation; New York: Springer-Verlag, 1985, ch. 4.

11. Tjrres E, Alejandro C. 2009. Modelling and optimization of Safety Instrumented Systems based on dependability and cost measures. http://etheses.whiterose.ac.uk

12. R. Gao, W. E. Wong, Z. Chen, and Y. Wang, "Effective Software Fault Localization using Predicated Execution Results," Software Quality Journal (online since November 11, 2015) (DOI 10.1007/s11219-015-9295-1) 
Kireeva E et al., International Journal of Emerging Trends in Engineering Research, 8(6), June 2020, 2878 - 2884

13. Pinto C, McShane M, Bozkurt I. System of perspective on risk: towards a unified concept. Int. J. of Systems Engineering. 2012. Vol. 3; 1:33 - 46.

14. Roghanian E, Moradinasab N, Afruzi E, Soofifard R. Project risk management using fuzzy failure mode and effect analysis and fuzzy logic.Int. J. of Services and Operations Management. 2015. Vol. 20, 2: $207-227$. https://doi.org/10.1504/IJSOM.2015.067477

15. Aaron Don M. Africa, Tomm Kenzo Dolores, MarkquisCasslin Lim, Lia Sophia San Miguel and Vincent Rafael Sayoc, Understanding Logical Reasoning Through Computer Systems, International Journal of Emerging Trends in Engineering Research, 2020. Vol.8, No. 4, PP. 1187 - 1191.

https://doi.org/10.30534/ijeter/2020/38842020

16. M.Sridhar, M. Ravi Kumar, J.Chandana, S.V.Pranitha, K.Y.Sahithi, Chella Santhosh, Detection of Various Adulterants Concentration levels in Gasoline Using NI-LABVIEW, International Journal of Emerging Trends in Engineering Research, 2020, Vol.8, No 4, PP.1247-1250.

https://doi.org/10.30534/ijeter/2020/49842020

17. D VenkataRatnam, Rakesh ChowdaryGutta, M. Ravi Kumar, L. Eswara Rao, M. V. Siva Surya Reddy, P. Sai Pavan, Chella Santhosh, Effect of High-K Dielectric materials on Mobility of Electrons, International Journal of Emerging Trends in Engineering Research, 2020, Vol. 8, No.2, PP. 314-316.

https://doi.org/10.30534/ijeter/2020/12822020 